\title{
Comer para vivir, comer hasta morir. Subjetividad y voracidad ${ }^{1}$
}

\author{
La grande bouffe | Marco Ferreri| 1973
}

\section{César Moreno-Márquez" y Alicia Mª de Mingo Rodríguez}

Universidad de Sevilla, España

Recibido: 16 de enero 2020; aceptado: 6 de junio 2020

\begin{abstract}
Resumen
Tomando como base de reflexión La grande bouffe, de Ferreri (1973), el presente artículo se propone mostrar hasta qué punto el comer constituye en el mundo contemporáneo un perfecto emblema de la sociedad de consumo y de la propia subjetividad. Después de que se separa de su sentido y de su sensatez como necesidad de nutrición, el comer se torna obsesivo. En lugar de "comer para vivir", nuestra voracidad e insaciabilidad (rasgos ya esenciales del ser humano) parecen abocar a un "comer hasta morir" o, como en el film de Ferreri/Azcona, a comer-para-la-muerte. Nos hemos convertido en tragones y glotones, en un delirio de exceso, como respuesta (absurda y, al mismo tiempo, lógica) a la imposibilidad de trascender la “ingestión” no sólo de alimento, sino de Todo. En este sentido, la última de las artes habría de ser el arte culinario, que deberá seducirnos para desear comer cuando ya no tengamos apetito. Por otra parte, desde el punto de vista ético, Ferreri/Azcona nos invitan a pensar, indirectamente, que mientras unos seres humanos mueren de inanición, nosotros morimos hartos en nuestra insaciable saciedad. El film de Ferreri se convierte, de este modo, en espejo muy actual del mundo contemporáneo y en una extraña apología irónica y triste, pero lúcida, -si se puede decir así- del seductor y mortífero arte de cocinar, que excita nuestra voracidad. Diez años después (1983), Creosota reventará, harto de comer, en El sentido de la vida.
\end{abstract}

Palabras clave: Arte culinario | Consumo | Glotonería | Obsesión | Sinsentido | Suicidio

Eating to live/Eating until death. Subjectivity and voracity

\begin{abstract}
Taking as a basis of reflection La grande bouffe (The Big Feast), by Ferreri (1973), this article intends to show to what extent eating constitutes in the contemporary world a perfect emblem of consumer society and of subjectivity itself. After it is separated from its meaning and good sense as nutritional need, eating becomes obsessive. Instead of "eating to live", our voracity and insatiability (already essential features of the human being) seem to lead "to eat until death" or, as in the Ferreri/Azcona film, to eat-towards-death. We have become swallows and gluttons, in a delirium of excess, as an answer (absurd and, at the same time, logical) to the impossibility of transcending the "ingestion" not only of food, but also of Everything. In this sense, the last of the arts should be the culinary art, which should seduce us to wish to eat when we no longer have an appetite. On the other hand, from the ethical point of view, Ferreri/Azcona invite us indirectly to think, that while some human beings are starving, we die fed up with our insatiable satiety. In this way, Ferreri's film becomes a very current mirror of the contemporary world and a strange, ironic and sad, but lucid, apology for the seductive and deadly art of cooking, which excites our voracity, if one may say so. Ten years later (1983), Creosota burst, fed up with eating, from Monty Python's The Meaning of Life.
\end{abstract}

Keywords: Culinary art | Consumption | Gluttony | Obsession | Meaningless | Suicide

Yo bebo por la sed venidera, yo bebo eternamente Rabelais, F. 1992, p. 50).

Lo ideal sería continuar comiendo así, indefinidamente Philippe Noiret, en La grande bouffe, Ferreri, M., 1973

pero tráigame el cubo, quiero vomitar (...) Lo quiero todo

M. Creosote en Monty Python's The Meaning of Life, Jones, T., 1983

La carencia jamás es dramática, lo fatal es la saturación Baudrillard, J., 1991, p. 38

\section{El comer como obsesión. \\ Nuestra insaciable saciedad}

Más allá de su función como satisfacción de una necesidad básica, imprescindible para la supervivencia, el comer se ha ido convirtiendo simbólicamente en un emblema de la sociedad de consumo, junto con la moda, el sexo o la tecnología. La creciente sensibilización contemporánea sobre el íntimo vínculo entre ingesta de alimentos y salud y, por otra parte, sobre la función so-

* Corresponding author: cesmm@us.es 
cial del comer ( La comida nos une» es el significativo lema del Canal Cocina televisivo), así como el avance experimentado en las últimas décadas por la gastronomía y el arte culinario, e incluso más recientemente, la preocupación en torno a las implicaciones ecológicas de la producción y consumo de alimentos, todo ello lo acredita. Si, según el conocido dicho tradicional, «hay que comer para vivir, no vivir para comer», se entiende que, aun reconociéndose la importancia de la comida para la vida, sin embargo, comer no debería dejar de ser un medio para convertirse en un fin, a la vista de su eficacia no sólo para proporcionarnos placer, amén de otros beneficios, sino también para concentrar en sí, del modo más inquietante, un potencial de goce capaz de convertir el comer, incluso autodestructivamente, en una cuasi infinita exigencia de satisfacción pulsional "digerible" por una insaciable e hiperproductiva cultura de consumo.

La sociedad consume comiendo, es una obviedad. La subjetividad que participa en ella encuentra en el comer no simplemente un medio de supervivencia, sino también, a efectos hermenéuticos, un modo de dar expresión a su estatus social, además de una eficaz válvula de escape para su creciente ansiedad, con lo que ello comporta. Si un conocido ensayo reclamaba hace años: más Platón, menos Prozac (Marinoff, 2000), lo cierto es que, hoy por hoy, el Prozac podría ser al menos complementado por una suficiente ingesta, según preferencias, de comida, sexo, deporte, viajes... A título siquiera "estético", cualquier flâneur en una gran ciudad se percataría, no sin asombro, de que "se" está comiendo a todas horas (propiciado por la amplísima oferta de establecimientos y por la diversidad de costumbres horarias de los turistas). Nos hemos convertido, masiva y sofisticadamente, en insaciables glotones, de acuerdo a la idea directriz del consumo a la carta como expresión del posmoderno proceso de personalización (Lipovetsky, 1986, p. 19.), lo que encuentra su correspondencia en que nunca como hoy, en la aldea global, hemos tenido inmediato acceso a tanto exotismo (incluso erotismo) culinario: más allá de rogar por «el pan nuestro de cada día», en nuestras coordenadas occidentales podemos afirmar que lo tenemos más que asegurado y de sobra, abarcando nuestro banquete desde "chucherías" o manjares de club-gourmet hasta cocina tradicional, a fuego lento, pasando por Fast Food, Dirty Food o Street Food.

Desde una perspectiva ética, resulta muy revelador de las paradojas humanas y de las dificultades para su resolución: el placer de comer y la abundancia de manjares facilita, por ejemplo, una obesidad, insana y considerada antiestética, que incita al consumo de dietas, tratamientos estéticos y quirúrgicos... Incluso podemos detectar cómo influyen estas tendencias incoherentes en el ámbito educativo, en tanto se inculca a los más pequeños el interés por una dieta sana y el valor del aprendizaje de técnicas culinarias, mientras que, al mismo tiempo, han ido surgiendo, con velocidad alarmante y cada vez a edades más tempranas, patologías alimentarias (anorexias, bulimias), sin duda propagadas socialmente.

En otro orden del contrasentido, a la vez que se investiga y explora cómo conseguir y utilizar recursos con vistas a una suficiente producción alimentaria local y global, por otra parte, casi todos los sectores productivos implicados aspiran a rentabilizar su actividad, conduciendo a una explotación extrema, abocada a una exponencial crisis ecológica. Finalmente, culminando con el absurdo, también se trata de los residuos generados y, en concreto, del problema de los excedentes alimentarios, lo que contrasta con su otro extremo paradójico y vergonzante: que haya una gran parte de la humanidad que, literalmente, "se" muere de hambre.

Y a nosotros, entretanto, nos amenaza la posibilidad de morir de hartazgo, a causa de nuestra insaciable saciedad. En otros tiempos, el cristianismo habría reconocido en ello el pecado de gula, que tendría su contrario sensato en la satisfacción del hambre, en el horizonte de sentido de la nutrición. Hoy, sin embargo, psicologizada, la gula se ha convertido en un trastorno alimentario.

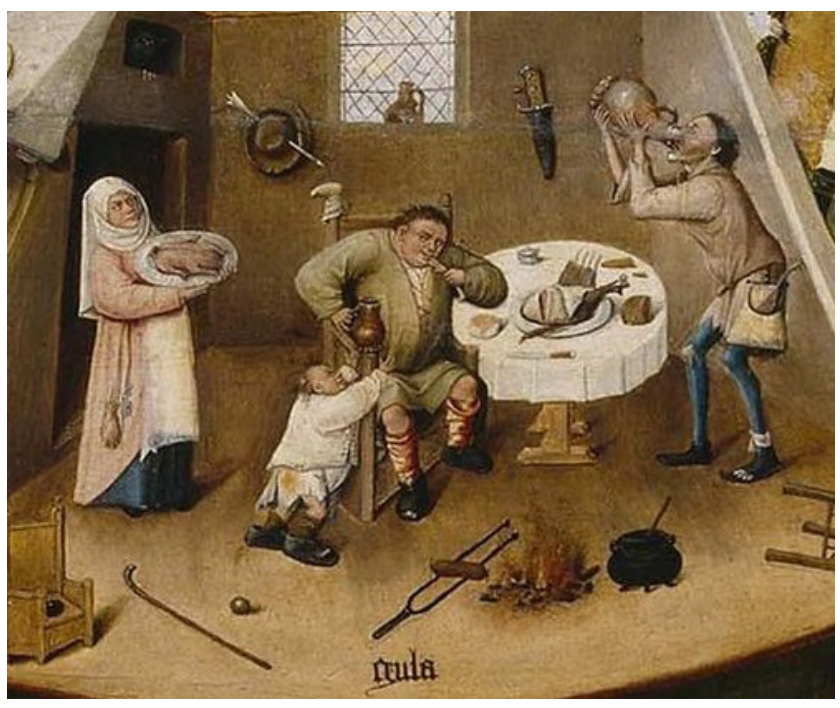

H. Bosco, Los pecados capitales (Gula) (1485). 


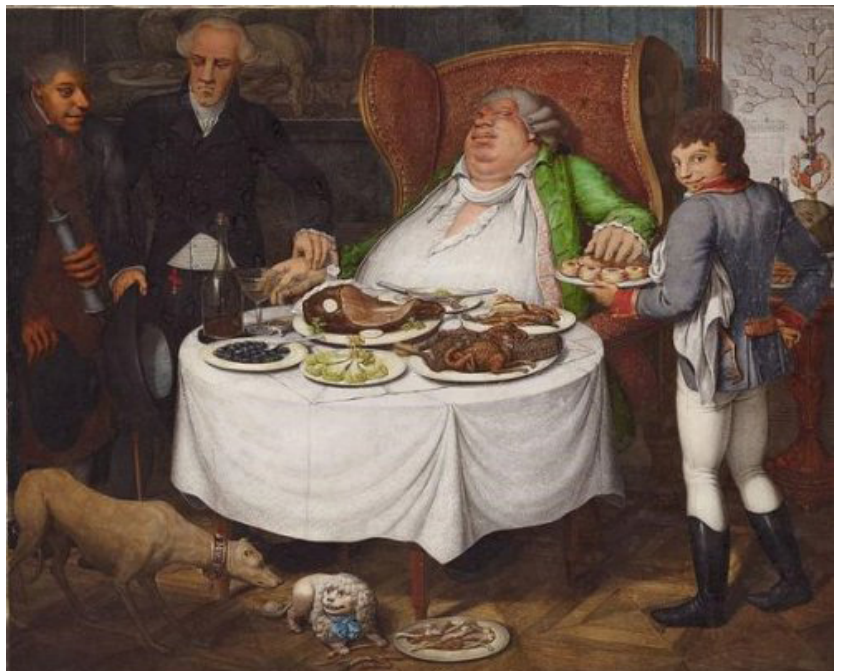

G. E. Opiz, La gula (1804).

Y, sin embargo, contra toda sobriedad y moderación, ¿es necesario que la saciedad sea, no ya obvia enemiga natural del hambre, sino rival cultural del deseo placentero de comer? Si no lo fuese, y en atención a la voracidad casi "ontológica" del ser humano, ¿por qué no seguir comiendo indefinidamente? El sentirnos mal como interrupción del placer nos ayudaría a desistir; pero cabría imaginar el goce de seguir comiendo sin hambre y sin fin, no porque se nos obligase, a modo de tortura, sino porque ejerciésemos la extraña libertad suicida, en nuestro caso, de desear-comer-hasta-morir, incluso-para-morir. ¿No podría ser perfecto, a su modo, ese comer despojado de su idea ${ }^{2}$ y de su verdad natural?

Deberíamos comprender la ordinaria locura de esta glotonería mortífera, convertida en signo de la subjetividad contemporánea y de nuestras sociedades. Adiós a la vulgar supervivencia. "¿Comamos, pues, sin hambre, comamos sin sentido, no paremos de comer!" Si "somos lo que comemos" (decía Feuerbach) y si vale decir, con Jean Anthelme Brillat-Savarin, "dime lo que comes y te diré quién eres” (en Fabris, 2019), iseamos!, y iseamos vorazmente! en el puro exceso del vivir para comer. Y si es preciso, en nuestra huida hacia adelante, decidamos sermás comiendo más, o dejar-de-ser no comiendo menos, sino comiendo más aún, hasta el fin: comamos hasta reventar o morir. Si estamos vacíos de sentido, ilusionémonos llenando al menos nuestros estómagos. Aquella memorable escena de Lo que el viento se llevó (Fleming, 1939) en que Scarlett O’Hara elevaba su puño al cielo, poniendo a Dios por testigo de que ya nunca más volvería a pasar hambre, es casi un homenaje a una cultura y una sociedad que no sólo no estará dispuesta a pasar hambre, sino que tampoco renunciará a su deseo insaciable de comer.

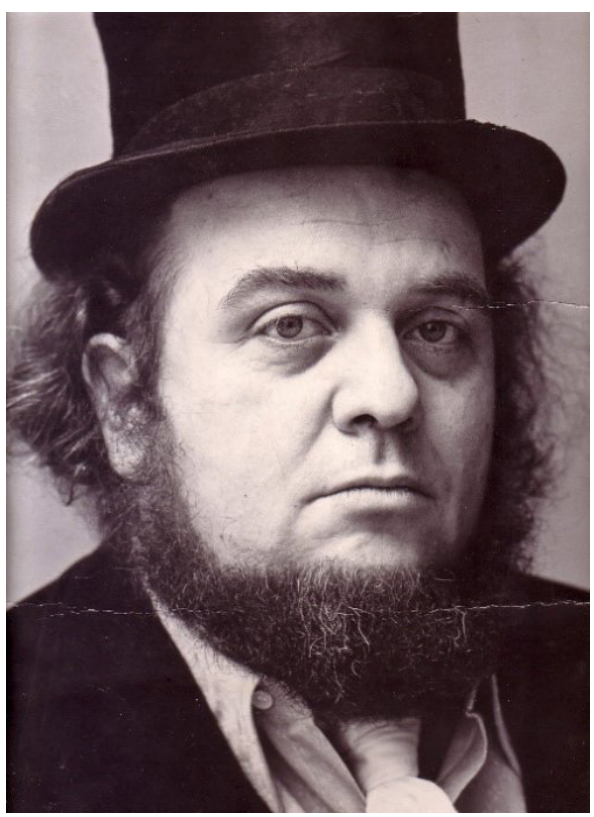

Marco Ferreri.

\section{La grande bouffe}

Si podemos pensar el desplazamiento desde el comer para vivir al vivir para comer, podremos acercarnos al comer-hasta-morir y comprender el desafío que supone para el espectador, aún hoy, más allá del reconocimiento que se le otorgó y de los escándalos que provocó en su momento (1973), aventurarse en la ficción propuesta por Marco Ferreri hace casi cincuenta años en La grande bouffe ( $L a$ gran comilona $)^{3}$, cinco años después de Mayo del 68, en una fecha muy próxima al advenimiento de la nowvelle cuisine francesa, y en una época en la que el cine aún era capaz de aventurarse descriptiva y críticamente en el devenir y la crisis contemporánea del sentido (Morandini, 1991). Habría muchos ejemplos memorables de ello, pero quizás aquí convenga recordar La naranja mecánica $(\mathrm{Ku}-$ brick, 1971), Saló o los 120 días de Sodoma (Passolini, 1976), El imperio de los sentidos (Oshima, 1976), o El último tango en París (Bertolucci, 1978).

Desde que comenzamos esta contribución no hemos pretendido sino introducir a La grande bouffe, film absolutamente serio, incluso en lo humorístico, histriónico y grotesco, obsceno y soez, ofensivo, transgresor e hipercrítico. El argumento es bien conocido, y no quisiéramos entretenernos demasiado con detalles: cuatro amigos se reúnen para comer. Nada de extraño, en principio. Se trata (por orden de aparición) de Ugo (Ugo Tognazzi), Michel (Michel Piccoli), Marcello (Marcello Mastroia- 
ni) y Philippe (Philippe Noiret). Un reparto estelar para una película que fuerza a los actores, tan reconocidos, a unas actuaciones muy arriesgadas ${ }^{4}$. El film los presenta al comienzo en sus vidas cotidianas: Ugo está casado y es chef en un restaurante, Michel está divorciado y se dedica al mundo de la televisión, Marcello es piloto de aviación comercial y un "maníaco sexual" (como dice de sí mismo), y Philippe es magistrado y convive, al cabo de los años, con su niñera, con la que mantiene encuentros sexuales. En cierto momento, se refiere a qué dirían sus compañeros de profesión si le vieran a él, a quien tienen por "un hombre serio".

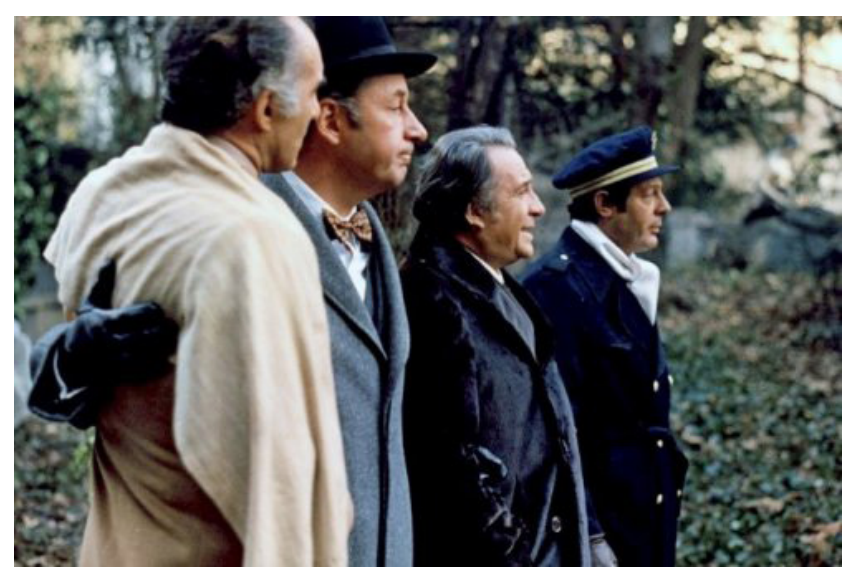

Michel, Philippe, Ugo y Marcello, a la llegada al caserón.

Nada, en principio, demasiado extraño -salvo notas surreales perfectamente escanciadas. Nadie en sus familias respectivas sabe propiamente dónde pasarán los días siguientes. Los cuatro se reúnen en un viejo y exótico caserón heredado por Philippe de su madre. Se trata, en realidad, de la casa en que vivió Octave Boileau, encontrándose en su jardín el conocido como "tilo de Boileau”, a cuyos pies el poeta solía hallar inspiración. Un camión llega con las viandas, que empiezan a ser descargadas y relatadas con gran lujo de detalles, pompa y circunstancia, a fin de que se aprecie que son productos de gran calidad. En cierto momento, Michel toma entre sus manos una cabeza desollada de res y tras declamar "Ser o no ser, esa es la cuestión" 5 (a lo que Ugo corresponde burlándose, imitando el sonido de una ventosidad), comienza a bailar con la cabeza de la res en sus manos. En el siguiente plano, el rostro crispado, inquietante, de Marcello dirá: “¡Comienza la fiesta!”, una fiesta a la que Philippe se ha referido antes, en conversación con un oriental (recurso surreal), como un "seminario gastronómico". Luego seguirá un primer atracón con ostras, mientras los cuatro visionan fotografías obscenas. Un momento antes han estado valorando y casi acariciando un bello bugatti que hay en un garaje de la casa. En los cuatro personajes no ha desaparecido, en absoluto, la sensibilidad estética. Es Ugo quien se encarga de preparar las suculentas comidas, que deben estimularles el apetito. A uno de ellos se le ocurre que podrían invitar a prostitutas, a fin de poder "redondear" un poco más el círculo del placer. También se suma Andrea (Andréa Ferréol), maestra de un colegio infantil colindante. Comoquiera que la actividad principal, obsesiva, es comer, las prostitutas pronto se irán, sorprendidas y hastiadas. Sin embargo, la maestra, al mismo tiempo inesperada amante del sexo y con sobradas dotes maternales ( $y$, como ella dice, incluso de "ama de casa”), se prodiga con los cuatro amigos, y permanecerá con ellos hasta el final.

En verdad, el film no desvela claramente que los cuatro personajes se han reunido o han constituido una suerte de "comunidad" para suicidarse comiendo-hasta-morir. Empresa difícil (como reconocerá Marcello en cierto momento, desesperado por tener que comer sin poder combinar la ingesta con la satisfacción de sus necesidades sexuales -una vez que se han ido las prostitutas), siendo que, incluso como placer, el comer no podría desvincularse por completo de la natural necesidad de satisfacer el hambre, de modo que la naturaleza nos advierte de no seguir comiendo cuando ya estemos saciados. Pero si no hay siempre hambre, pero sí tanta abundancia de comida frente al escaso sentido de la vida, ¿por qué no hartarse de comer, hasta morir? ¿No sería envidiable poder morir comiendo? Y así sucede en el film. Los cuatro mueren: Marcello, Michel, Ugo y Philippe. No es baladí que al final de la película Philippe muera sentado bajo el tilo de Boileau. Donde antes había poesía, en un jardín que podemos imaginar cuidado y florido, lo que resta es un jardín abandonado y un hombre que muere ahíto, en brazos de Andrea, momento al que de inmediato sucede en el film la llegada de un camión con más viandas.

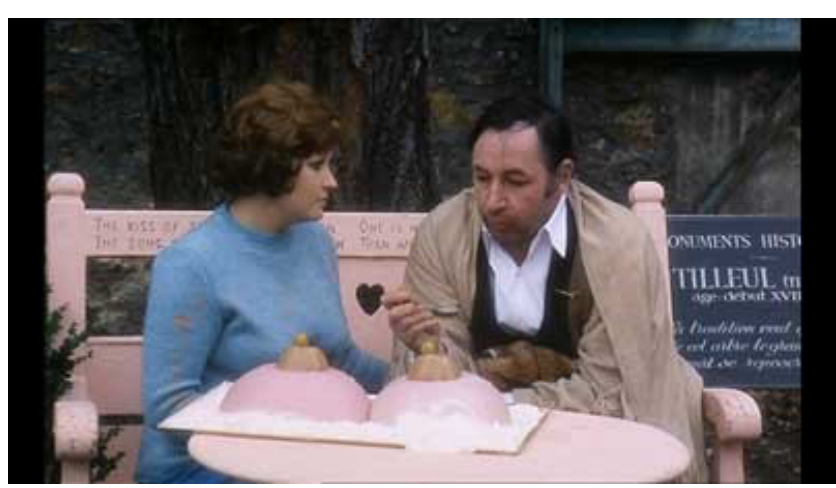

Andrea regala a Philippe, bajo el tilo del poeta Boileau, su último plato. 
El guión del film, a cargo de Marco Ferreri y Rafael Azcona, reconocido por sus colaboraciones memorables con, sobre todo, García Berlanga, y que ya había trabajado en los años 50, en España, con Ferreri en El pisito y El cochecito, no se prodiga en reflexiones.

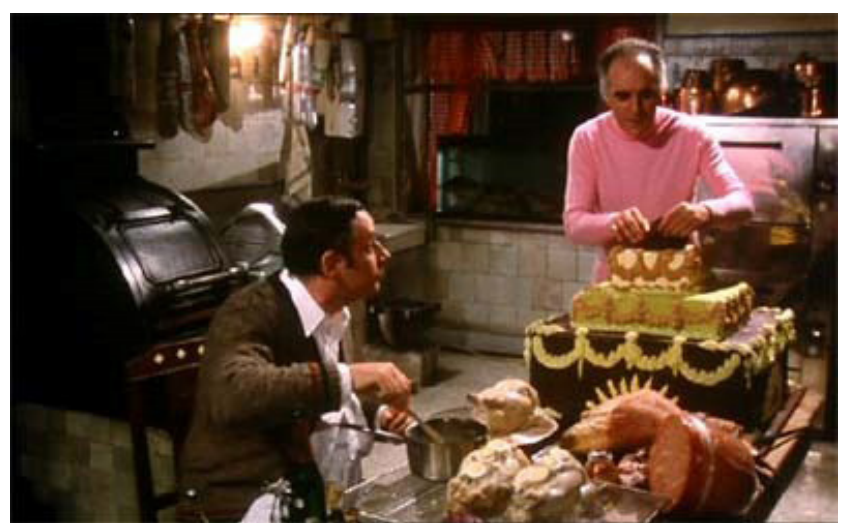

Philippe y Michel preparan la comida.

\section{Vacíos de sentido y hartos hasta la muerte}

Si de La grande bouffe pudiera desprenderse una figura de la subjetividad contemporánea, sería la del Glotón. Más filosóficamente: la del Devorador, el Insaciable. Los personajes quieren llenar su vacío existencial atiborrando sus estómagos, como si el "espíritu" se hubiese convertido en estómago. O quizás con el argumento según el cual, "Ya que apenas nos queda "espíritu" y sentido, tengamos estómago: un gran estómago". Pero no sólo se trata de eso. Es cierto que en el film aparecen en muchas ocasiones expresiones del placer que procura el comer (otro placer sería el del sexo, o el de la cultura) pero, como dice Michel en cierto momento, hacia la mitad del film: "Aparte de la comida, todo es epifenómeno: la arena, la playa, el esquí, el amor, el trabajo, tu cama. Epifenómeno. El Eclesiastés dice: Vanitas vanitatis. Come. Come, come más. Come, come, ¡come más!”. Un poco después, una de las prostitutas, en verdad aún figuras-de-sensatez, se preguntará: “¿Por qué comen, si no tienen hambre? Es ridículo".

La comunidad que forman los cuatro amigos se ha puesto de acuerdo no en comer hasta la saciedad, lo que sería asumible, sino en comer más allá de la saciedad, contra un hipotético (y natural) límite del deseo. Se trata de hacer verdad no el consabido "si no comes te mueres", sino el "si no comes no te mueres" (como dice Ugo a Michel cuando éste "no puede más"), que trastoca por completo el sentido del placer, a medias entre la necesidad y el deseo ${ }^{6}$. Pero la clave no viene dada por el simple "si no comes", sino por el añadido "si no comes más..." para pasar al "hay que seguir comiendo".

Pero, en verdad, ¿qué implica este comer? En el film, la crítica cultural de Ferreri no se dirige propiamente al sujeto depredador, sino al sujeto devorador, es decir, al consumidor insaciable, contranatura y absurdo, pero perfectamente acorde con una libertad que puede desear la auto-aniquilación del sujeto: máxima libertad hasta morir y para morir. Que Ferreri eligiese el comer era imprescindible, en la medida en que constituye, más que la moda, el sexo o la tecnología (a los que nos referíamos al comienzo), el núcleo irreductible del vivir, y siendo aquello cuya falta conduce a la muerte. Cuya falta... o cuyo exceso, hasta sus últimas consecuencias. Ferreri y Azcona consiguen así situar el deseo de morir contra la voluntad de vivir en la zona de las necesidades más esenciales y perentorias, acercando el sinsentido a lo que es necesario a la vida.

O dicho de otro modo: director y co-guionista se dirigen a la subjetividad y la sociedad, sumidas en una descomunal crisis de sentido. Lo que está en juego es el exceso y la insaciabilidad. El comer se convierte en justificación de una producción masiva de alimentos, que no sería el efecto de alguna causa "objetiva" (como el aumento de población, por ejemplo), sino justamente la consecuencia de una subjetividad que devora, que aspira a, y espera -pero también desespera de-, ser "satisfecha" mucho más allá del hambre que podrá ser saciada. Esto es lo que está en juego. Por ello, a nuestro juicio, los comentarios sobre el film que inciden en la hipercrítica a la sociedad de consumo serían válidos, aunque no primordiales, si su lectura no fuese meramente sociológica; y del mismo modo, entendemos que la crítica a la burguesía se aleja del núcleo de significación más esencial de la película, lo que no implica que nos parezca intrascendente ${ }^{7}$. Lógicamente, quienes pueden permitirse un festín de tales características deben tener capacidad adquisitiva, del mismo modo que han de ser "profesionales", representando diversos estratos de la sociedad: el poder (Philippe), la cultura (Michel), la aventura (Marcello) y el arte (Ugo) (Torreiro, $\left.1991^{\circ}\right)$. Cuando comenzamos hablando de la sociedad de consumo fue con el propósito de llegar al nexo antropológico-existencial entre el sujeto que consume y el sujeto consumido por su propia insaciabilidad como íntimo motor del consumo, que Ferreri ubica en el horizonte de, dicho 
heideggerianamente, nuestro ser-respecto-a-la-muerte, una muerte acelerada, precipitada, en tanto abordada desde la posibilidad del suicidio.

Lo que está en juego, pues, no es simplemente la conversión cultural de la necesidad fisiológico-natural del comer en el deseo de comer -por ejemplo, de acuerdo a exigencias de diversidad, sofisticación, etc. Lo que se dilucida es la figura alterada de una subjetividad entregada al exceso de comer, capaz de asumir el culmen del sinsentido: morir voluntariamente por el exceso de lo que nos permite vivir. El film muestra nuestra civilización en una suerte de delirante huida-haciaadelante: moriremos de tanto comer, de tanto consumir. La escena final es casi serenamente apocalíptica. Cuando ya los cuatro amigos han muerto, y sólo resta Andrea y los perros, aún llegará otra furgoneta con más comida, que se quedará, por orden de la maestra, en el jardín, para que se la coman los perros. La consumición se ba consumado en la aniquilación de los consumidores. La comida no tendrá seres bumanos que se la coman.

Tengamos siempre hambre -o aparentemos tenerla. Pero no erremos la lógica: seremos víctimas de nuestra propia insaciabilidad. Se puede tener hambre y esperar descansar placenteramente en la saciedad. El hambre que está, por el contrario, en juego, es un hambre que apela al Hambre (escribámosla con mayúscula) como goce mortífero. Tengamos hambre hoy y sigamos comiendo por el hambre que tendremos mañana. Extraño argumento, al estilo de aquel personaje de Gargantúa que figuraba en uno de nuestros exergos. Ante la amenaza del hambre, comamos más: como si pudiésemos acumular así, ante el riesgo de un hambre futura. Los hambrientos deberán estimular, renovándola, el hambre de los saciados (nos referiremos luego a ello con más detalle).

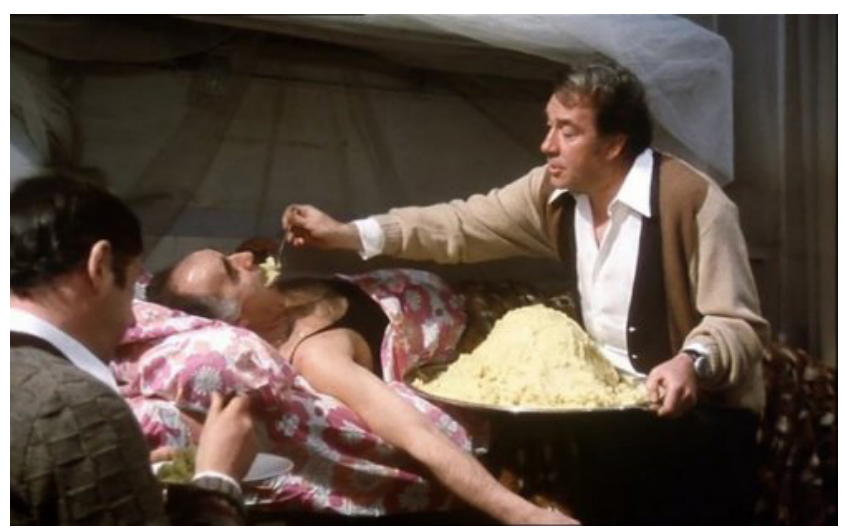

«Come, si no comes, no te morirás».

\section{De lo primordial a lo escatológico. Apocalipsis excrementicio}

Sin duda, la dimensión más "humorística" del film, y cualquier diría que también más soez e incluso obscena (de no ser porque alguien a la altura de 1973 se dejase escandalizar más -lo que sería previsible- por algún desnudo integral), radica propiamente en el desfile de sucesos "escatológicos" que aparecen en la película. Algún vómito y, sobre todo, flatulencias, especialmente las de Michel. En verdad, Ferreri no se prodiga (podría haberlo hecho) en mostrar la "cara B", excremencial, del "seminario gastronómico" ". En todo caso, nos reserva la sorpresa, que también lo es para los personajes, de cómo una tubería con excrementos se rompe "explosivamente", cayendo sobre Marcello, para gran jocosidad, casi hasta el atragantamiento, de Ugo. En palabras de Michel, un diluvio universal de mierda, complemento grotesco perfecto de las sonoras flatuencias de Michel -a quien Ferreri reserva la apariencia menos digna de la muerte.

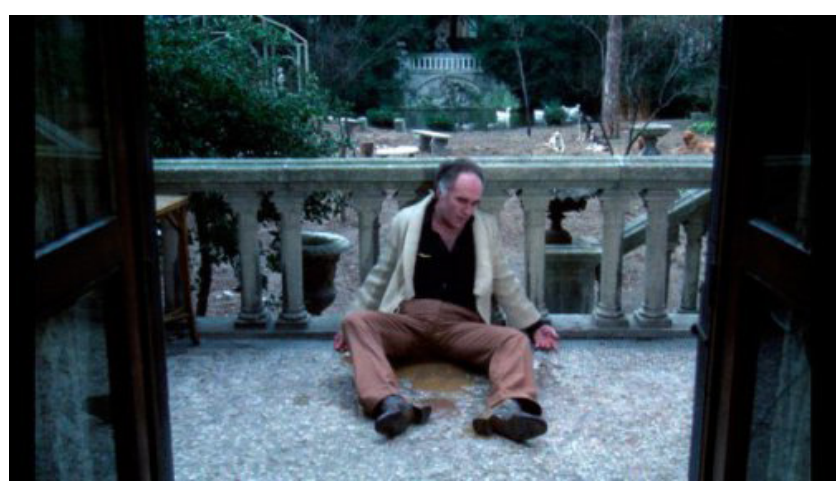

Muerte de Michel.

La verdad de la insaciabilidad exige también la otra-verdad de la exigencia de vaciar para poder seguir manteniendo activa la repleción. En la dinámica de la insaciabilidad son decisivos el estímulo del deseo, para ir contra corriente de la mera necesidad de comer, y la exigencia de evacuar. Nuestra capacidad devoradora genera la parte inasimilable, que debemos desechar. A diferencia de otros placeres, el de la comida comporta la verdad de un destino inquebrantable: ingerir exige defecar. No se puede "jugar" a la insaciabilidad si no se apuesta al mismo tiempo por la excrementalidad. A diferencia de la basura y de su reciclado, los excrementos producidos no ya por los alimentos, sino por su ingesta y digestión, carecen de reciclado. Las flatulencias de Michel nos lo recuerdan con frecuencia, pues nos 
permiten, ya que no ver, sí al menos escuchar lo que está teniendo lugar allí dentro, en la interioridad digestiva. La gran deglución no simplemente nos rodearía de todo lo devastado (animales y plantas), sino también del máximo de excrementos ${ }^{10}$. Si el espectador del film, a la altura de 2020, se anima a extraer conclusiones acerca de un planeta inundado de desechos, estará en su completo derecho a hacerlo y tendrá toda la razón de su parte.

Ciertamente, habrá de comprenderse bien el alcance casi metafísico del tema. No sólo se trata de ingerir comida, sino de ingerir todo, el Todo, lo que quiera que sea. Los desechos no habrán de ser sólo excrementos intestinales en su curso fisiológico, sino desechos en general. Si la ingesta no tiene que ser sólo nutritiva, todo habrá de poder ser excretado. Sólo en Andrea parece cumplirse la posibilidad de una ingesta nutritiva, no pervertida, lo que se deja notar en que es quien manifiesta abiertamente que tiene hambre y está, como suele decirse, "entrada en carnes", casi como un personaje rubensiano en su papel de amante y madre. Ferreri -se lo constata en muchas ocasiones en el film- estaba fascinado con su rostro extasiado.

\section{El arte culinario, o la última de las artes}

Para no morir de desgana ante la expectativa de un hartazgo acorde a la vuelta de tuerca del deseo de insaciabilidad, imprescindible para su potencial mortífero, es preciso convocar, in extremis, a la que habría de ser la última de las artes. Nos referimos, claramente, al arte culinario, es decir, al arte de cocinar. En el horizonte del sinsentido, y en las desmotivaciones que comporta, sólo podría quedar, como último acicate del deseo, el arte culinario. No es preciso avisar a un médico que pueda aliviar el malestar o el dolor, y menos aún "sanar" -porque aquí ya no se muere por enfermedad alguna-, ni siquiera se ha de llamar, en principio, a ninguna funeraria, pues los cadáveres son introducidos en un enorme frigorífico que hay en la cocina. No hay que llamar a Nadie. Sólo es necesario el Cocinero, pero un magnífico cocinero, capaz de seguir motivando, con sus maravillas culinarias, el deseo de comer-sin-ganas. Y a buen seguro que Ugo se esmera en ello, a veces sin el éxito deseado, especialmente al final del film, que culmina con un solitario atracón de patés por parte de Ugo, habiendo comenzado la comilona -ya fue dicho- con un atracón "comunitario" de ostras.

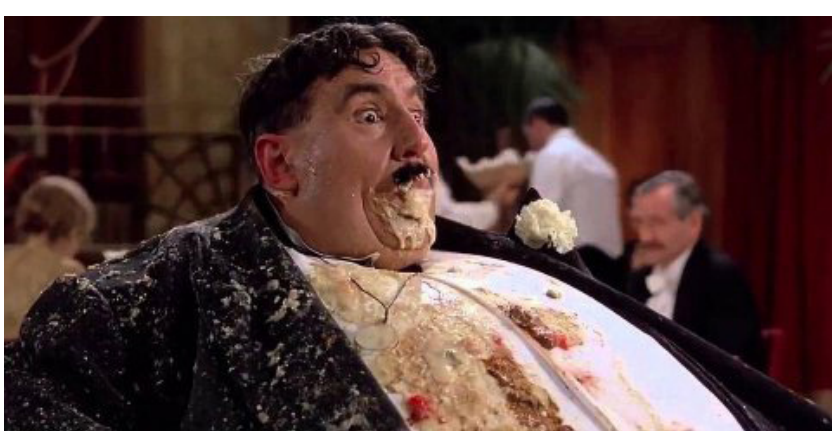

Creosota vomitando en El sentido de la vida (T. Jones, 1983).

\section{Final. Para una ética de La grande bouffe}

Cuando en cierto momento Michel, que ha tenido un feroz ataque de flatulencia, dice a Ugo que no quiere seguir comiendo, Philippe le estimula diciendo que es cuestión de voluntad. Y añade: "Imagina que eres un niño hindú en Bombay. Y que estás hambriento, muy hambriento. Si estás muy hambriento ¿̇ué haces? jcomes!..." Y luego añade Ugo: "Come, si no comes, no te morirás".

En el culmen de nuestra absurda insaciable saciedad, ¿no podría pensar el insensato que sería perfecto que muriésemos, no de hambre -como mueren tantos, lejos-, sino de hartura? Si, en el fondo, tenemos que expiar la culpa de nuestros excesos, absurdos e injustos, mientras otros mueren de hambre, mientras desolamos la Tierra, y nada de todo ello tiene sentido alguno, jexpiemos la culpa muriendo hartos, hartos hasta reventar, pero que hasta el final nos acompañe, en común, el goce (ya más que el placer). Si estamos hartos de tanto vacío, hartémonos llenándonos... de aquello que habría de mantenernos a todos los seres humanos (también a los que mueren hambre) con vida (el alimento), pero que nosotros, al expiar la culpa de nuestro exceso y despilfarro, haremos que nos mate. Mostremos que estamos hartos hasta la muerte, irremediablemente hartos, hartos incluso de estar hartos, hartos de nuestra insaciabilidad, y hartos de nuestra saciedad -y de nuestra sociedad, y de nosotros mismos. La ingesta sin sentido es sólo la última expresión mortífera, suicida, del sinsentido generalizado. Nuestra voracidad no nos matará de hambre, sino de insaciable saciedad. No se trataría aquí simplemente, aunque pudiera disfrazarse de tal modo, de una posibilidad "surreal". Ya que parece que no nos percatamos lo suficiente, recordémoslo: mostremos (es lo que hace Ferreri) que moriremos por ello. Tiene que poderse re- 
cordar este absurdo con un redoble de tambor o con un aullido, o con todos los medios de que dispongamos. Si algo de sensatez restase en el sujeto voraz, hagámosle recordar que podemos morir de hartazgo.

¿Hay, pues, una ética de La grande bouffe? A nuestro juicio, el film trata de mostrar al espectador el delirio autodestructivo de un ser humano y de una sociedad que, habiendo perdido el sentido de vivir, asume su autodestrucción bajo la forma justamente del Sinsentido. Si el sentido del comer es la nutrición o el placer, aparte de otras recompensas, los personajes de La grande bouffe asumen el sinsentido del comer apostando por el comer por-el-comer-mismo, de modo que éste queda "enloquecido" por su propia insaciabilidad. Ferreri nos ayuda a pensar en qué medida lo hemos asumido y nos estamos autodestruyendo en esta insaciabilidad irrefrenable. Si el signo de la civilización es el devorar continuamente, el hartazgo acabará con nosotros al mismo tiempo que el afán de devorar acabará con lo Otro, que será sometido a un proceso de deglución sin fin. Lo que nos matará será, en términos heideggerianos, haber perdido la serenidad respecto al comer ${ }^{11}$... Pero digámoslo mejor: la serenidad respecto al devorar (que es el verdadero motor), no importa si devoramos comida, sexo, moda, tecnología... lo que quiera que sea. El devorar será, a la postre, devastador.

Pues bien, en el fondo, de eso se trata. En su visión fílmica, Ferreri asume la perspectiva de los devoradores. El espectador asiste, curioso, al desenvolvimiento de los sucesos, percatándose de la locura que implica comer sin ganas, por el puro afán de comer. El medio, en suma, se convierte en fin. Por ello, se pasa del comer para vivir al vivir para comer, y desde éste al comer-hasta-morir, una especie, si se nos permite decirlo así, de comer-respecto-a-la-muerte. La sabiduría popular siempre lo comprendió cuando se percató de la potencia patógena e incluso mortífera del comer en exceso. La distan- cia que separa el primer atracón de ostras del atracón de paté por parte de Ugo da cuenta de que el comer, fuera-del-sentido, se vuelve contra el alimento y contra el placer. Lo terrible de la situación planteada por Ferreri es que el absurdo se ha situado en la entraña de la vida, en la compulsión del comer como fin en sí mismo, sin sentido. Que la subjetividad y la sociedad contemporánea se expongan a ello es una posibilidad real, y el film de Ferreri denuncia esta situación. Salir asqueado o inquieto del visionado de La grande bouffe tiene un efecto terapéutico-catárquico, en la medida en que comprendemos que no-hay-salida, que es preciso emprender otra vía.

A mediados del pasado siglo, Lévi-Strauss (1988) culminaba, casi “ponía la guinda” a Tristes trópicos con la crítica a nuestro furor civilizatorio y alabando el impulso a "suspender el trabajo de colmena", a fin de encontrar una serenidad que el etnógrafo cifraba

en la contemplación de un mineral más beᄀllo que todas nuestras obras, en el perfume, más sabio que nuestros libros, respirado en el hueco de un lirio, o en el guiño cargado de paciencia, de serenidad y de perdón recíproco que un acuerdo invo $\neg$ luntario permite a veces intercambiar con un gato. (p. 468)

Necesitamos una ética no simplemente del “comer”, sino una ética más global del sentido, al menos, si no como respuesta a nuestras posibles grandes preguntas, sí al menos una ética del sentido como mesura, equilibrio y sostenibilidad; recuperar al menos la búsqueda del sentido contra la amenaza nihilista de la desesperación por su ausencia, que devuelva también el sentido del comer (en general, como relación con lo Otro) a la sabiduría de la nutrición como equilibrio a favor de la vida compartida. El arte culinario, la dimensión social del comer... suponen las bellas puntas del iceberg de la glotonería contemporánea, dispuesta a devorarlo todo, a todas horas, poniéndolo Todo a disposición de un comer sin fin... ni sentido.

\section{Referencias}

Baudrillard, J. (1991). La transparencia del mal. Ensayo sobre los fenómenos extremos. Barcelona, España: Anagrama.

Company, J.M. (1991). El lugar de la ausencia. Ferreri desde el psicoanálisis. En E. Riambau (Ed.), Antes del apocalipsis. El cine de Marco Ferreri (pp. 93-102). Madrid, España: Cátedra.

Dauman, A. (productora) y Oshima, N. (director). (1976). El imperio de los sentidos [cinta cinematográfica]. Japón: Argos Films. Fabris, A. (2019). Etica del mangiare. Cibo e relazione. Pisa, Italia: Edizioni ETS.

Grimaldi, A. (productor) y Bertolucci, B. (director). (1972). El último tango en París [cinta cinematográfica]. Italia: United Artists.

Grimaldi, A. (productor) y Pasolini, P.P. (director). (1975). Saló o los 120 día de Sodoma [cinta cinematográfica]. Italia: Produzioni Europee Associate; Les Productions Artistes Associés 
Goldstone, J. (productor) y Jones, T. (director). (1976). El sentido de la vida [cinta cinematográfica]. EEUU: Universal Pictures.

Guarner, J.L. (1991). Cómo subvertir géneros tradicionales en cuatro lecciones (que podrían ser más) a cargo del profesor Marco Ferreri, aproximadamente transcritas por el estudiante José Luis Guarner. En E. Riambau (Ed.), Antes del apocalipsis. El cine de Marco Ferreri (pp. 59-66). Madrid, España: Cátedra.

Heidegger, M. (1988). Serenidad. Barcelona, España: Ediciones del Serbal.

Hénaff, M. (1980). Sade. La invención del cuerpo libertino. Barcelona, España: Ediciones Destino.

Kubrick, S. (productor y director). (1971). La naranja mecánica [cinta cinematográfica]. Reino Unido: Warner Bros; Hawk Films.

Lévi-Strauss, C. (1988). Tristes trópicos. Barcelona, España: Paidós.

Lipovestky, G. (1986). La era del vacío. Ensayos sobre el individualismo contemporáneo. Barcelona, España: Anagrama.

Malle, V. y Rassam, J.-P. (productores) y Ferreri, M. (director). (1973). La grande bouffe [cinta cinematográfica]. Italia/Francia: Mara Films / Les Films 66 / Capitolana Films.

Marinoff, L. (2000). Más Platón y menos Prozac: filosofía para la vida cotidiana. Barcelona: Ediciones B.

Morandini, M. (1991). El moralista apocalíptico: Ferreri en los años setenta. En E. Riambau (Ed.), Antes del apocalipsis. El cine de Marco Ferreri (pp. 49-55). Madrid, España: Cátedra.

Rabelais, F. (1992). Gargantúa. Madrid, España: Alianza Editorial.

Riambau, E. (1991). Introducción. En E. Riambau (Ed.). Antes del apocalipsis. El cine de Marco Ferreri (pp. 7-10). Madrid, España: Cátedra.

Selznick, D. (productor) y Fleming (director). (1939). Lo que el viento se llevó [cinta cinematográfica]. Estados Unidos: Metro-Goldwyn-Mayer; Selznick International Pictures.

Torreiro, C. (1991). La muerte de la máscara. El actor en el cine de Ferreri. En E. Riambau (Ed.), Antes del apocalipsis. El cine de Marco Ferreri (pp. 67-74). Madrid, España: Cátedra.

1 Esta investigación se inserta en el Proyecto de Investigación (Excelencia) «Dinámicas del cuidado y lo inquietante. Figuras de lo inquietante en el debate fenomenológico contemporáneo y las posibilidades de la Orientación Filosófica» (FFI2017-83770-P), Gobierno de España.

2 Ya lo había atisbado Baudrillard (1991): “Cuando las cosas, los signos y las acciones están liberadas de su idea, de su concepto, de su esencia, de su valor, de su referencia, de su origen y de su final, entran en una autorreproducción al infinito. Las cosas siguen funcionando cuando su idea lleva mucho tiempo desaparecida. Siguen funcionando con una indiferencia total hacia su propio con-

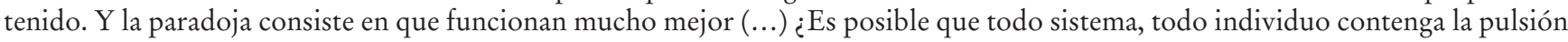
secreta de liberarse de su propia idea, de su propia esencia, para poder proliferar en todos los sentidos, extrapolarse en todas direcciones? Pero las consecuencias de esta disociación, sólo pueden ser fatales. Una cosa que pierde su idea es como el hombre que ha perdido su sombra; cae en un delirio en el que se pierde" (pp. 12-13).

En palabras de Esteve Riambau (1991), “Ante un cine profundamente visceral, como el que ha realizado Marco Ferreri desde hace más de treinta años, la indiferencia o el escepticismo son actitudes prácticamente excluidas. Un film como La gran comilona, cuya reflexión sobre los límites de la sociedad de consumo sólo es accesible para el espectador desde el momento el que éste se sumerge con los personajes del film en una textura física que incluye algunos de los estadios más desagradables del ciclo biológico, sólo puede tener, en consecuencia, grandes admiradores o profundos detractores. Por otra parte, el cineasta milanés es el primer interesado en borrar sus propias huellas a lo largo de una filmografía cuya principal característica radica en el hecho de que cada una de sus obras ha sido realizada como una respuesta inmediata, visceral -insisto en el término-, frente a una serie de elementos determinantes de su entorno sociológico" (p. 7). En todo caso, insistiremos más adelante en que, a nuestro juicio, el "calado" de la propuesta de Ferreri en general, y de La gran comilona, en particular, no se reduce a una perspectiva de crítica sociológica.

$4 \quad$ Es interesante la observación de Casimiro Torreiro (1991), que refiriéndose al hecho de que Ferreri recurra con frecuencia a grandes actores, dice que, a pesar de ese recurso, "Ferreri llega a resultados que nunca contradicen sus intenciones. O para decirlo en otras palabras, que el efecto star system (...) que podría lastrar o incluso distorsionar la plasmación de un cine personal en una perspectiva autoral, en el caso de Ferreri no sólo no lo hace, sino que ese efecto se vuelve como un boomerang contra el espectador, atrapado entre la imagen -impuesta, deseable y deseada- de su ídolo y la desacralización a menudo corrosivamente irónica a que se presta ese mismo ídolo cuando se pone en manos de Ferreri y da vida a un personaje que, en la abrumadora mayoría de los casos, es poco más que un mono atrapado en los insondables vericuetos de su propia impotencia” (p. 68).

5 Volverá a aparecer hacia el minuto 46.

6 Insistimos en que cuando nos referimos a la eclosión del comer no estamos pensando en el gesto individual de comer, sino en éste como gesto global, en la promoción del ingerir a todas horas, en cualesquiera circunstancias, bajo no importa con qué motivo.

7 En todo caso, la reflexión de J.M. Company (1991) es muy valiosa: “Los burgueses del film, al igual que los libertinos de Sade -y ésta es, sin duda, la ficción más sadiana de la historia del cine- se encierran para evidenciar la crisis de su mundo. Y, por el hecho de 
darse desde el exclusivo punto de vista de la clase dominante, el circuito capitalista de producción y consumo queda plasmado como tal, en su pura facticidad. En La gran comilona se palpa la auténtica y real alienación de un sistema que, al no generar plusvalías, se vuelve contra el propio cuerpo de sus dirigentes (...), dando lugar a la simple constatación escatológica del excremento, el vómito y la muerte. Al no existir progresión de la historia ni caracterización gratificante de los personajes que propicie la identificación del espectador, la película funciona como continua reiteración de un espacio clausurado donde los personajes se autocondenan a producir su propia muerte. Y es que, al explicitar lo no decible de la cultura burguesa -la obscenidad de la muerte, lo excedentario del detritus- Ferreri nos habla también de su descomposición” (p. 99).

8 Véase la excelente caracterización del film que lleva a cabo Torreiro (1991) en las páginas 65-66.

$9 \quad$ Para Morandini (1991) “la genialidad y la fuerza traumática del film -el más macabro y sádico de Ferreri- residen en la tranquila lucidez de la mirada y en la rigurosa honradez que el director conserva incluso cuando lleva un asunto maternal y corporal hasta las consecuencias extremas" (p. 53).

10 Hénaff (1980), en su magnífico comentario del pensamiento de Sade, insiste en que «los desechos del cuerpo (...) continúan siendo verdaderamente irrecuperables, incalificables (...) Apenas pueden resultar de una teratología: no tienen ni siquiera la fascinación de lo monstruoso; lo que evocan es el horror gris y familiar de lo vil, de lo nulo, de lo miserable. En suma, "mierda": con lo cual el nombramiento vulgar se confiesa como el pleonasmo de una preclusión; de todas aquellas sobre las que se establece la cultura, ésta es la más violenta y por tanto la más necesaria; no debe dejar rastros ni memoria de sí; está fuera de la historia, disuelta en la más total amnesia. No es ni siquiera del orden de lo negativo: no tiene contrario; es más bien el "reverso disyuntivo" de la cultura. Y sin embargo es en el borde de ese oscuro foso de abyección donde ésta levanta con más provecho su cara sublimada» (p. 218).

11 Heidegger (1988) se refirió a la exigencia de mantener una cierta distancia respecto a la tecnología, a fin de que ésta no nos atrapase y alienase por nuestro furor del dominio del mundo. La serenidad exige no-querer y dejar-ser-lo-Otro (p. 36). 